\title{
Role of CREB signaling in aging brain
}

\author{
V. PARAMANIK ${ }^{1,2}$, M.K. THAKUR ${ }^{1}$ \\ ' Biochemistry and Molecular Biology Laboratory, Centre of Advanced Study, \\ Department of Zoology, Banaras Hindu University, India; \\ 2 Department of Zoology, Varanasi, India Department of Zoology, \\ Indira Gandhi National Tribal University, Amarkantak, India
}

\begin{abstract}
A B S T R A C T
During aging, brain undergoes several changes which influence its function through alteration in the expression of genes. Some of these genes are regulated by estrogen which requires a host of coregulator proteins including CREB. In brain, CREB is expressed in different regions and regulates a wide range of functions such as cellular growth, proliferation and memory in response to a variety of intracellular signaling events including synaptic efficacy and long-lasting changes in synaptic plasticity. In response to signals at the cell surface, CREB is phosphorylated in the nucleus by various protein kinases via secondary messengers such as $c A M P$ and/or $C a^{+2}$ for regulating specific genes. Alterations in CREB signaling lead to cognitive deficits as observed in normal aging and neurodegenerative diseases. In brain, the expression of CREB changes with age, but its variation with sex is not known. $S o$, in this review paper, we summarize recent findings indicating age and sex dependent expression of CREB and its interaction with estrogen receptor $(E R) \beta$, and the role of CREB signaling in brain aging and diseases. Such understanding of CREB signaling through ER may help to design therapeutic strategies for age related cognitive deficits and neurodegenerative disorders.
\end{abstract}

\author{
Key words \\ Brain $\bullet$ CREB signaling $\bullet$ Estrogen Receptor $\beta \bullet$ Aging
}

\section{Introduction}

During aging, brain undergoes several changes at structural, molecular and cellular levels leading to alteration in its functions. Some of these changes are linked to the action of estrogen which binds to its cognate estrogen receptor (ER) and interacts with target genes after recruiting a host of coregulator proteins including cAMP response element-binding protein (CREB) (McKenna and O'Malley, 2002; Heldring et al., 2007; Thakur and Paramanik, 2009). Several studies have demonstrated that CREB activates expression of hundred of genes in response to a large number of extracellular stimuli (Lonze and Ginty, 2002). It regulates various activity-dependent gene expressions in the brain. Extracellular signals at the cell surface activate secondary messengers such as cAMP and/or $\mathrm{Ca}^{+2}$, that in turn stimulate protein kinases, which are translocated into nucleus and phosphorylate CREB. The pCREB interacts with target genes and regulates various biological functions, viz. cellular growth, proliferation and memory. Similar events also occur in response to a variety of intracellular signaling events like facilitation of short-term memory to long-term memory in the hippocampus (Silva et al., 1998), synaptic efficacy and long-lasting changes in synaptic plasticity (Silva et al., 2009; Saura and Valero, 2011). CREB is expressed in different regions of the brain including prefrontal and hippocampus. Its level decreases in the brain of aged rodents and dementia patients (Porte et al., 2008; Satoh et al., 2009). Any altera- 
tion in CREB signaling can contribute to cognitive deficits during aging and increased incidence and progression of neurodegenerative diseases such as Huntington's disease, Alzhemier's disease and Parkinson's disease (Satoh et al., 2009).

A variety of review and research articles describing CREB, brain functions and aging were consulted for this review. The idea of this paper was to discuss CREB signaling and aging in brain along with new finding from our laboratory. Here, we showed expression of CREB and its interaction with ER $\beta$ during aging in both sexes, and discussed role of CREB signaling in brain aging and diseases. Such understanding of CREB signaling through ER may help to design therapeutic strategies for age related cognitive deficits and neurodegenerative disorders.

\section{CREB signaling and brain functions}

CREB was initially identified as a transcription factor for the somatostatin gene (Montminy and Bilezikjia, 1987). It is a $43 \mathrm{kD}$ protein belonging to the CREB/ATF-1 family of transcription factors, conserved from Drosophila to humans and highly studied in relation to brain (Shaywitz, 1999; Carlezon, 2005). In mammals, CREB family members include CREB, cAMP-responsive element modulator (CREM) and activating transcription factor 1 (ATF-1). CREB and ATF-1 are ubiquitously expressed in all tissues including brain. CREB is a central signal transduction molecule which activates a large number of cellular genes containing cAMP response elements (CREs) and regulates several functions such as cellular growth, memory and neuronal proliferation. CREB is involved in the formation of long-term memory in the marine snail Aplysia, Drosophila melanogaster and rats (Dash et al., 1990; Bartsch et al., 1995). It is necessary for the late stage of long-term potentiation and plays an important role in the development of drug addiction (DiRocco, 2009; Nazarian, 2009; Wang, 2009). CREB is also important for the survival of neurons in genetically engineered mice, where CREB and CREM were deleted in the brain. The mechanism of CREB signaling is very complex. Briefly, in response to a variety of cellular and mitogen stress signals like peptide hormones, neurotransmitters, calcium influx and growth factors (Shaywitz, 1999;
Mayr and Montminy, 2001) at the cell surface, secondary messengers such as cAMP and/or $\mathrm{Ca}^{+2}$ are activated resulting in the activation of protein kinases. Thereafter protein kinases are translocated into nucleus for phosphorylating CREB. Several kinases including PKA activate CREB, and phosphorylate the kinase inducible domain (KID) at serine133 (Johannessen et al., 2004). The pCREB binds as a dimer to CRE (5'-TGACGTCA-3') via its basic leucine zipper (bZIP) domain and recruits the coactivator $\mathrm{CBP}$ and p300 to mediate transcriptional activation (Chrivia et al., 1993; Kwok et al., 1994; Arias et al., 2004). These coactivators then promote the recruitment of components of the basal transcriptional machinery to initiate transcription of CREB target genes (Sandoval, 2009). A schematic representation of CREB signaling through ER $\beta$ is shown in Fig. 1.

A leading paradigm of regulation is the activation of CREB, $\mathrm{Ca}^{2+}$ and CBP (Sheng et al., 1990; Johannessen et al., 2004). CREB can be activated through phosphorylation at Ser-133 and other residues with possible functional consequences (Matthews, 1994; Sun et al., 1994), Ser-133 has been the predominant focus of studies of transcriptional regulation and it can be caused by electrical activity (Davis et al., 2000), neurotransmitter or hormone action on G-protein-coupled receptors (Liu et al., 1996; Yan et al., 1999), or neurotrophin effects on receptor tyrosine kinases (Ginty et al., 1994; Finkbeiner et al., 1997). The richness of CREB signaling is greatly increased by its responsiveness to multiple intracellular signal transduction cascades (Wu et al., 2000).

In addition, CREB activity is regulated by a family of cytoplasmic coactivators known as transducers of regulated CREB activity (TORCs). TORC members, TORC1, TORC2 and TORC3, are strong activators of CREB-dependent transcription and bind the bZip domain of CREB in response to extracellular stimuli, such as cAMP, calcium and hormones. When activated, TORCs are translocated into the nucleus where they activate CREB through a phosphoserine-133 independent mechanism (Conkright, 2003; Screaton, 2004). It has been implicated in a number of cellular events. CREB coactivators help to discriminate between signals to activate only specific cellular processes. However, it has been demonstrated that the interaction between CREB 


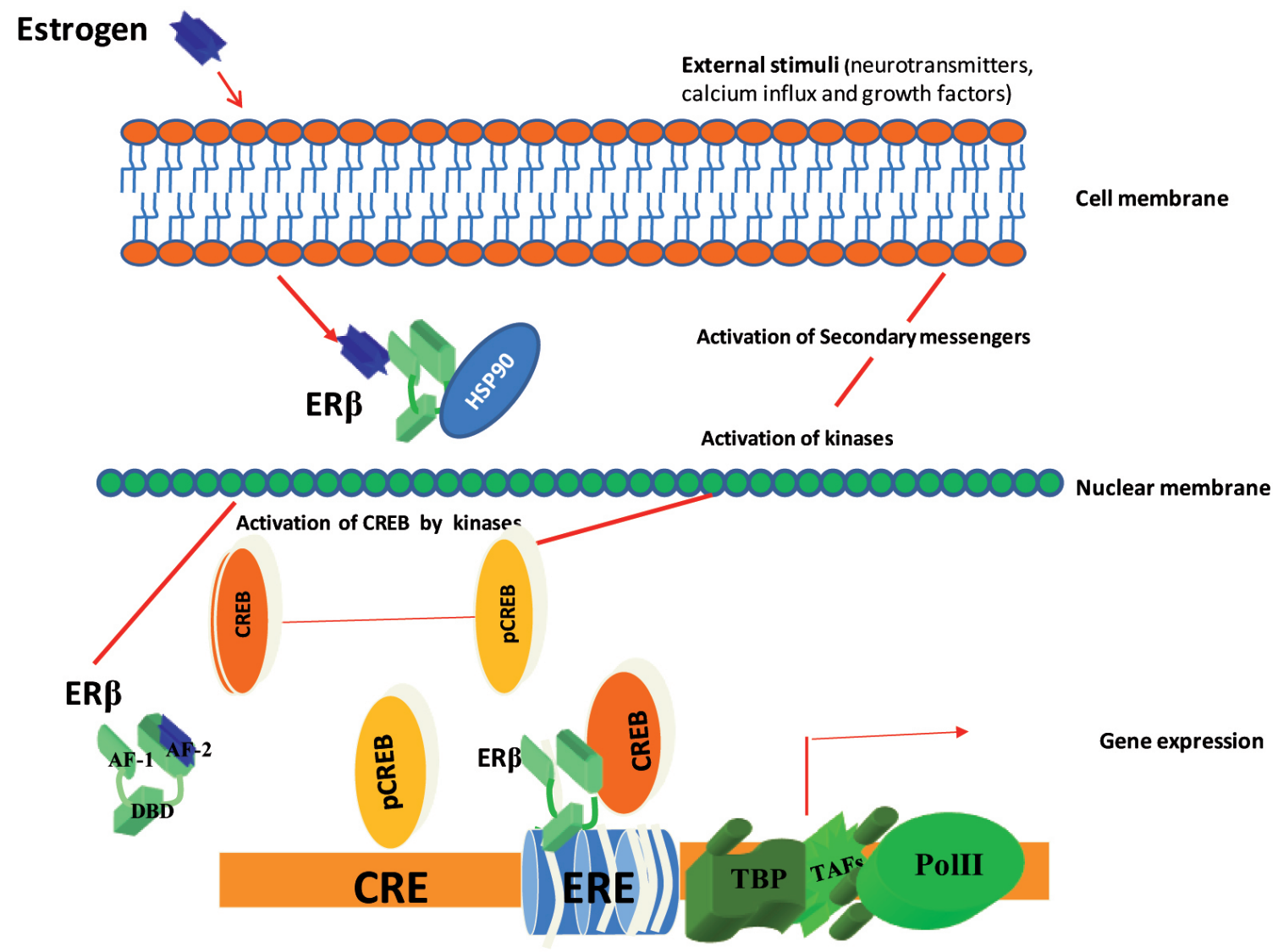

Fig. 1. - Schematic representation of CREB signaling through ER $\beta$. In response to multiple extracellular stimuli such as neurotransmitters, calcium influx and growth factors), activation of secondary messengers occurs, followed by activation of kinases, which phosphorylates CREB in the nucleus. Thereafter PCREB binds to CRE (CREB regulatory element) of target gene and recruit ER $\beta$ for specific gene regulation. On the other hand, after binding to its cognate ligand estrogen in cytoplasm ER $\beta$ is dissociated from heat shock protein (HSP), dimerized and translocated to nucleus, binding to estrogen responsive element (ERE) of the target gene and recruit CREB for specific gene regulation.

and its coactivators are weak to activate transcription of CREB target genes (Sandoval et al., 2009). This suggests that many CREB interacting proteins are yet to be identified which can potentiate CREB activation or confer signal specificity. In addition, there are very few papers suggesting the possible involvement of CREB in brain cognitive reserve studies. Environmental enrichment increases CREB expression that serve as one of the important factors in cognitive reserve (Nithianantharajah and Hannan, 2009).

For the last one decade, a number of laboratories including ours are involved in studying CREB and other interacting proteins of ER in the brain (Brann et al., 2008; Thakur and Paramanik, 2009). Such studies may be useful to understand estrogen related brain functions and disorders.

\section{CREB in aging brain}

CREB is expressed in different regions of the brain including prefrontal and hippocampus and shows changes during aging (Kim et al., 2010). The levels of total or pCREB are reduced in the hippocampus of old mice and rats (Brightwell et al., 2004; Kudo et al., 2005; Porte et al., 2008). The effect of aging on CREB seems to be specific for the hippocampus because changes in pCREB are not observed in the frontal cortex of old rats (Williams et al., 2008; Xu et al., 2010). Further, deregulation of pCREB after learning rather than changes in its level has been linked to impairments of synaptic plasticity and memory during aging (Kudo et al., 2005; Monti et al., 2005; Countryman and Gold, 2007). Decreased pCREB and memory performance occurring during 
aging is linked to an increase in $\mathrm{Ca}^{+2}$ influx mediated by L-type voltage gated channel and NMDA receptor (Foster and Kumar, 2002). Disruption of CREB function has been associated with several pathways during aging. The number of CBP positive cells is decreased in CA1, CA3 and dentate gyrus of the hippocampus and cortex of aged in comparison to adult rats, suggesting the possibility for age-related deficits in CREB-dependent transcription (Chung et al., 2002). Decreased levels of CaMKII, CaMKIV, MAPK and pCREB are reported in the hippocampus of old rats coinciding with spatial memory deficits (Chung et al., 2002; Williams et al., 2008; Xu et al., 2010). In addition, decreased level of phosphorylated PKAC $\beta$ has been reported in old mice and senescence accelerated mouse prone-8 (SAMP8) (Li et al., 2009a). Moreover, cAMP/PKA signaling is differently affected by aging in the hippocampus and frontal cortex of rats and rhesus monkeys (Karege et al., 2001; Ramos et al., 2003).

In spite of many studies of CREB with aging, interaction of pCREB and CREB with ER $\beta$ and their expression as a function of age and sex are not known. So we conducted in-silico studies using STRING 8.0, BIND, PIP and DIP to identify ER $\beta$ interacting proteins in mouse brain. Pull down assay using purified and functionally active ER $\beta$ (Paramanik and Thakur, 2010a, 2011a) showed fourteen proteins in the range of $30 \mathrm{kD}-185 \mathrm{kD}$. These ER $\beta$ interacting proteins were identified as estrogen receptor associated protein (ERAP) 140 (Paramanik and Thakur, 2010b), amplified in breast cancer (AIB)1 (Paramanik and Thakur, 2011b), Trk A and Src (Thakur and Paramanik, 2011) in the brain. They showed age and sex dependent expression and interaction with ER $\beta$. ER $\beta$ interacting proteins of $45 \mathrm{kD}$ and $43 \mathrm{kD}$ were identified as pCREB and CREB, respectively, by immunoblotting and immunoprecipitation (Paramanik and Thakur, 2012). For analyzing the age and sex dependent change in interaction and expression, immunoprecipitation and immunoblotting were performed respectively. Interestingly, pCREB interacted with ER $\beta$ in adult male only whereas young and old did not show interaction in the detectable range. On the other hand, in female, the interaction was higher in adult and lower in young than old. Further, the interaction of CREB, as compared to young, increased significantly in adult and decreased in old male. In female, the inter- action was higher in young, and lower in adult than old (Fig. 2A, B). In male, the expression of pCREB was similar in young and old, but increased significantly in adult. However, in female, the expression was significantly higher in adult than both young and old. The expression of CREB decreased significantly in adult and old as compared to young male, but showed no significant change in female (Fig. 2C, D). Earlier reports suggest that CREB expression decreased in cerebral cortex and in the hippocampus (Asanuma et al., 1996), suprachiasmatic nucleus (Coll et al., 1998) in aged rats, and in the senescent fibroblast of aged hamsters (Zhang et al., 1996). Further, downregulation of CREB-mediated transcription results in decrease of CREB content in the hippocampal neurons of $\mathrm{AD}$ brain which may contribute to disease progression (Pugazhenthi et al., 2011). The interaction of CREB with ER $\beta$ may play a significant role as it depends on the level of estradiol and ER $\beta$ recruitment to promoters, which may decline as a function of age in both sexes.

The higher interaction of pCREB and CREB with ER $\beta$ in the brain of young mice of both sexes can be correlated with higher neurogenesis, higher learning capacity and signal transduction for the cell migration (Pekcec et al., 2008). The lower interaction of CREB and pCREB with ER $\beta$ in both sexes may be correlated with lower level of neurosteroids and estrogen in old mice (Levine and Stadtman, 2001). Functional loss of CREB in developing mouse embryo leads to death of mice immediately after birth, highlighting the critical role of CREB in promoting survival. Thus the lower interaction in old age may be correlated to neuronal death, less capacity for learning and higher expression of the CREB in old may be correlated for promoting survival of the neurons. Such alteration of pCREB and CREB interaction with ER $\beta$ and their age and sex dependent interaction and expression may be useful to understand estrogen mediated signaling through ER $\beta$ during aging.

\section{Alteration of CREB signaling and diseases}

Genetically engineered flies over express inactive CREB and lose their ability to retain longterm memory (Dworkin and Mantamadiotis, 2010). 
(A)

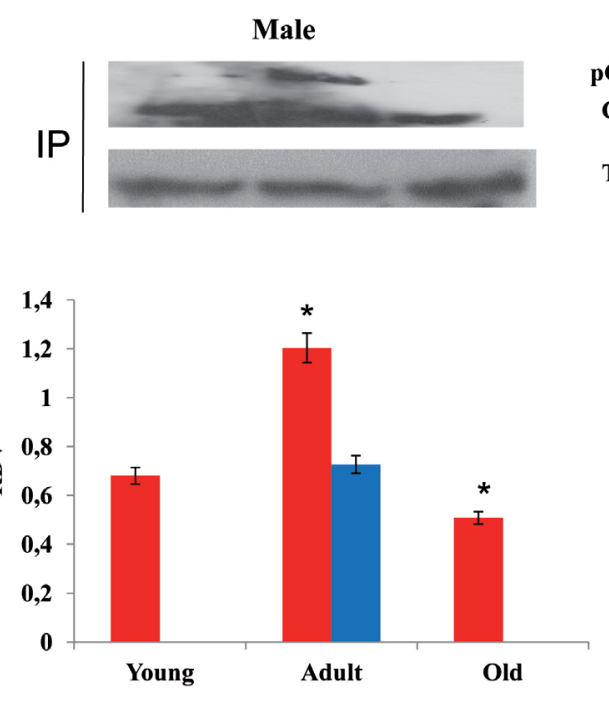

pCREB
(B)
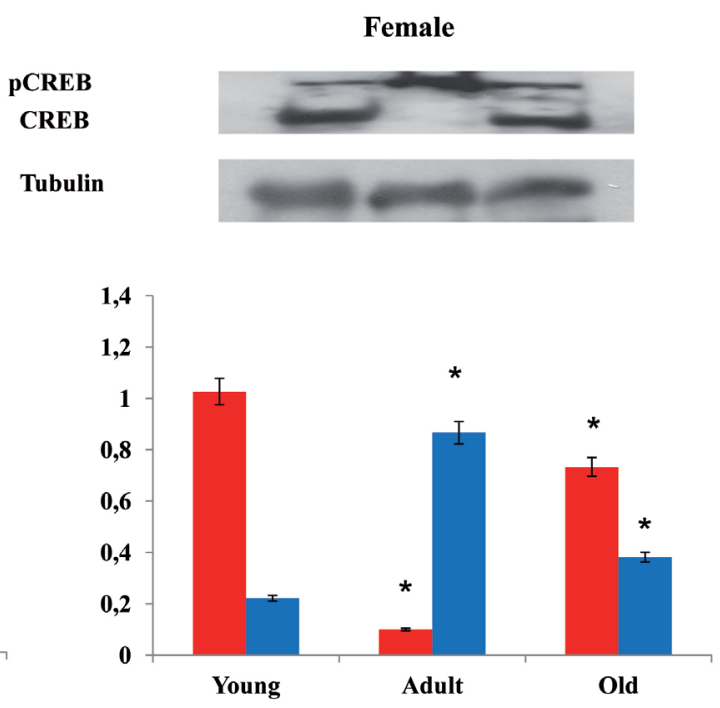

CREB
(C)
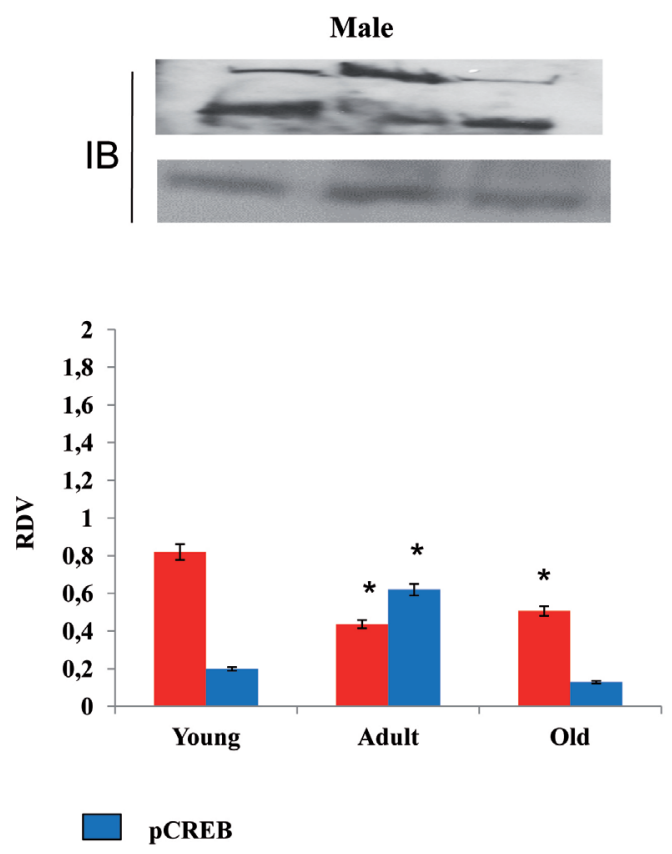

(D)
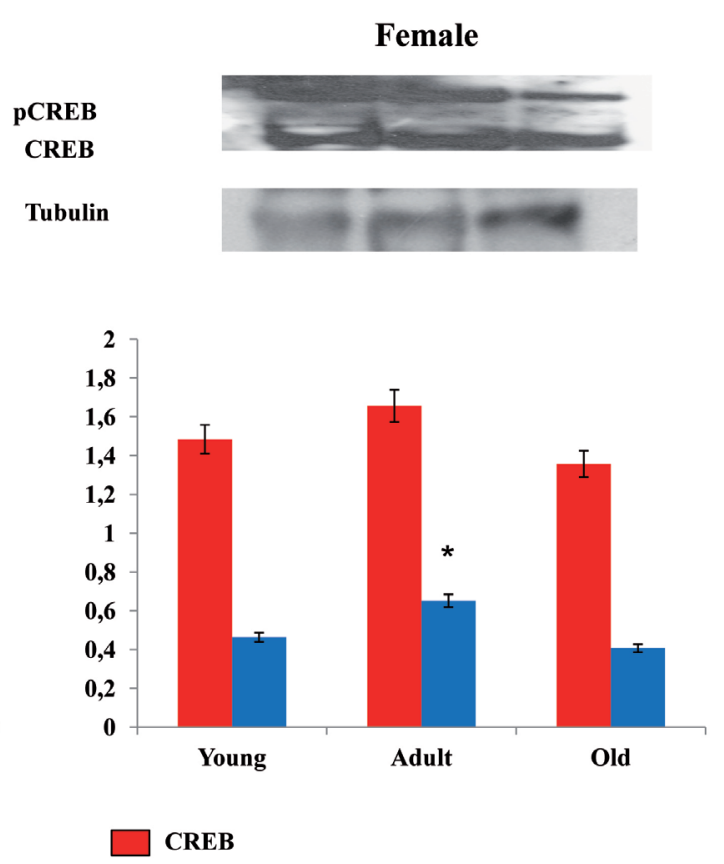

Fig. 2. - Immunoprecipitation (IP) of nuclear extract from the brain of young (6 weeks), adult (25 weeks) and old (70 weeks) mice with ERß and immunoblotted with PCREB and CREB. (A) Male (B) Female, and immunoblotting (IB) of nuclear extract from young (6 weeks), adult (25 weeks) and old (70 weeks) mice brain showing expression of PCREB and CREB. (C) Male (D) Female. For both IP and IB, beta tubulin III was used as loading control. Histogram represents relative density value (RDV) with SEM from three independent experiments. Data were statistically analyzed using a one-way ANOVA comparing age, followed by all pairwise multiple comparison procedure (StudentNewmann-Keuls method). Young was taken as control for comparison with adult and old. The $p$ values $<0.05$ were considered as significant. " represents significant difference. 
Disturbance of CREB function in brain can contribute to the development and progression of Huntington's disease, $\mathrm{AD}, \mathrm{PD}$ and cognitive deficits in aging (Dworkin and Mantamadiotis, 2010). Deregulated phosphorylation of CREB after learning rather the changes in the basal levels of pCREB has been linked to impairment in learning and memory during aging (Countryman and Gold, 2007; Saura and Valero, 2011). Accumulation of $\beta$-amyloid $(A \beta)$ peptides and neurofibrillary tangles are typical neuropathological lesions of $\mathrm{AD}$ brain and neuronal dysfunction with cognitive problem (Jack et al., 2010). Recent evidences showed that the effect of $\mathrm{A} \beta$ on hippocampal synaptic plasticity, memory and synapse loss is mediated by the CREB signaling. Previously, it was demonstrated that $\mathrm{A} \beta 42$ reduced PKA activity and disrupted long term potentiation in hippocampal slices, reduction in pCREB and endocytosis of NMDA (Vitolo et al., 2002; Snyder et al., 2005). A $\beta 42$ oligomers inhibit phosphorylation of CREB in primary neurons via a mechanism involving reduction of NMDA receptors (Ma et al., 2007). Further, the negative effect of $A \beta$ on CREBdependent transcription was induced by cAMP and $\mathrm{Ca}^{2+}$ signals (España et al., 2010). Furthermore, evidences of CREB dysfunction on memory loss and neurodegeneration in $\mathrm{AD}$ are based on studies in presenilin (PS) mutant mice. Inactivation of PS in the forebrain of PS conditional double knockout (cDKO) mice leads to early hippocampal-dependent spatial and associative memory deficits. These deficits are NMDA receptor-mediated responses and coincide with reduced expression of CREB/ CBP-dependent target genes, suggesting the role of CREB signaling (Saura et al., 2004). Pen-2, an essential component of the $\gamma$-secretase complex that triggers endoproteolytic cleavage of PS1 is regulated by CREB (Wang et al., 2006). These findings suggest the possibility for a reciprocal regulation of $\mathrm{PS} / \gamma$-secretase and CREB signaling during activitydependent synaptic function and disturbance leading to diseases.

The crucial role of CREB signaling underlying synaptic plasticity and memory has led to the hypothesis that targeting CREB could be a potential therapeutic strategy for memory disorders (Tully et al., 2003). Plant extracts containing natural antioxidants improve learning and memory in aged animals, presumably by increasing the levels of pCREB and its kinases. Age-related memory deficits in C57BL/6 and SAMP8 mice improved after long-term treatment with green tea catechins (a type of flavonoid) by enhancing CREB and PKA (Li et al., 2009a, b). Treatment of old rats with blueberry extracts, which are enriched with flavonoids, does not manifest the memory impairment and decreased levels of pCREB with age (Williams et al., 2008). Flavonoids increased phosphorylation of CREB, ERK1/2 and CaMKIV in aged memory-impaired rats (Xu et al., 2010). Long-term treatment with ginsenoside, an active component of ginseng root, delays hippocampal-dependent memory impairments in very old mice by maintaining levels of pCREB, CaMKII, PKA and NMDA receptor (Zhao et al., 2009). Altogether, these results indicate that natural plant extracts delay memory deficits associated with aging by maintaining normal levels of active CREB.

\section{Concluding remarks and future directions}

CREB expression and signaling have been widely studied in the brain. Substantial attempts have been made to understand the mechanisms regulated by CREB in long-term synaptic plasticity and memory. The involvement of CREB in brain development and neurogenesis in the adult, suggests that dysfunction of CREB during neurogenesis can be involved in cognitive deficits. Further, CREB is known to facilitate memory by increasing synaptic efficacy and allocation of cells, but CREB signaling within a memory circuit in memory decline upon aging and age related neurodegenerative diseases is still unclear. Now, specific CREB-dependent gene regulation in neuronal function is beginning to emerge in the hippocampus of dementia patients with cognitive deficits, and here we showed a link between CREB and ER $\beta$ in aging brain. Taking together, it raises the challenges as well as opportunity to understand CREB signaling through ER $\beta$ (Fig. 1) in the brain. Such understanding may be helpful in the development of therapeutic strategies by regulating the level of CREB and $\mathrm{ER} \beta$, affected in age and neurological disorders.

CREB regulates multiple affects in the brain is an established fact. ER $\beta$ recruits CREB for age and sex dependent gene expression is evident from this paper. Thus manipulation of ER $\beta$ and/or CREB may 
result healthy brain aging and used for the treatment of neurodegenerative diseases. The manipulation of CREB could be possible by various means such as environmental enrichment, genetic, molecular studies in animal and cellular model. On the other hand ER $\beta$ could be supplemented with food and steroid containing compound. Taken together, the understanding of CREB signaling through ER may help to design therapeutic strategies for age related cognitive deficits and neurodegenerative disorders.

\section{Acknowledgement}

The authors thank Dr Vincent Giguere, Canada, for providing pCMX-mouse ER $\beta$ and Dr Marc R Montminy, USA, for providing $\mathrm{pCREB}$ and CREB antibody as a kind gift. Financial support from the Indian Council of Medical Research (ICMR) and Department of Biotechnology (BT/PR3593/ Med/14/468/2003), Government of India, to MKT and Senior Research Fellowship from ICMR to VP, are highly acknowledged.

\section{References}

Asanuma M., Nishibayashi S., Iwata E., Kondo Y., Nakanishi T., Vargas M.G., Ogawa N. Alterations of cAMP response element-binding activity in the aged rat brain in response to administration of rolipram, a cAMP-specific phosphodiesterase inhibitor. Brain Res. Mol. Brain Res., 41: 210-215, 1996.

Arias J., Alberts A.S., Brindle P., Claret F.X., Smeal T., Karin M. Activation of cAMP and mitogen responsive genes relies on a common nuclear factor. Nature, 370: 226-229, 1994.

Bartsch D., Ghirardi M., Skehel P.A., Karl K.A., Herder S.P., Chen M. Aplysia CREB2 represses long-term facilitation: relief of repression converts transient facilitation into long-term functional and structural change. Cell, 83: 979-992, 1995.

Brann D.W., Zhang Q.G., Wang R.M., Mahesh V.B., Vadlamudi R.K. PELP1-A novel estrogen receptor-interacting protein. Mol. Cell Endocrinol., 290: 2-7, 2008.

Brightwell J.J., Gallagher M., Colombo P.J. Hippocampal CREB1 but not CREB2 is decreased in aged rats with spatial memory impairments. Neurobiol. Learn. Mem., 81: 19-26, 2004.

Carlezon W.A., Duman R.S., Nestler E.J. The many faces of CREB. Trends Neurosci., 28: 436-445, 2005.
Chrivia J.C., Kwok R.P., Lamb N., Hagiwara M., Montminy M.R., Goodman R.H. Phosphorylated CREB binds specifically to the nuclear protein CBP. Nature, 365: 855-859, 1993.

Chung Y.H., Kim E.J., Shin C.M., Joo K.M., Kim M.J., Woo H.W., Cha C.I. Age-related changes in CREB binding protein immunoreactivity in the cerebral cortex and hippocampus of rats. Brain Res., 956: 312-318, 2002.

Coll S.D., Ip N.Y., Lindsay R.M., Wiegand S.J. Expression of BDNF and trkB as a function of age and cognitive performance. Brain Res., 812: 200208, 1998.

Conkright M.D., Canettieri G., Screaton R. TORCs: transducers of regulated CREB activity. Mol. Cell, 12: 413-423, 2003.

Countryman R.A. and Gold P.E. Rapid forgetting of social transmission of food preferences in aged rats: relationship to hippocampal CREB activation. Learn. Mem., 14: 350-358, 2007.

Dash P.K., Hochner B., Kandel E.R. Injection of the cAMP-responsive element into the nucleus of Aplysia sensory neurons blocks long-term facilitation. Nature, 345: 718-721, 1990.

Davis S., Vanhoutte P., Pages C., Caboche J., Laroche $\mathrm{S}$. The MAPK/ERK cascade targets both Elk-1 and cAMP response element-binding protein to control long-term potentiation-dependent gene expression in the dentate gyrus in vivo. J. Neurosci., 20: 45634572, 2000.

DiRocco D.P., Scheiner Z.S., Sindreu C.B. Chan G.C., Storm D.R. A role for calmodulin-stimulated adenylyl cyclases in cocaine sensitization. $J$. Neurosci., 29: 2393-23403, 2009.

Dworkin S. and Mantamadiotis T. Targeting CREB signalling in neurogenesis. Expert. Opin. Ther. Targets 14: 869-879, 2010.

España J., Valero J., Miñ ano-Molina A.J., Masgrau R., Martin E., Guardia-Laguarta C., Lleo A., GimenezLlort L., Rodriguez-Alvarez J., Saura C.A. $\beta$-amyloid disrupts activity dependent gene transcription required for memory through the CREB coactivator CRTC1. J. Neurosci., 30: 9402-9410, 2010.

Finkbeiner S., Tavazoie S.F., Maloratsky A., Jacobs K.M., Harris K.M., Greenberg M.E. CREB: A major mediator of neuronal neurotrophin responses. Neuron, 19: 1031-1047, 1997.

Foster T.C. and Kumar A. Calcium dysregulation in the aging brain. Neuroscientist, 8: 297-301, 2002.

Ginty D.D., Bonni A., Greenberg M.E. Nerve growth factor activates a Ras-dependent protein kinase 
that stimulates c-fos transcription via phosphorylation of CREB. Cell, 77: 713-725, 1994.

Heldring N., Pike A., Andersson S., Matthews J., Cheng G., Hartman J. Estrogen Receptors: How do they signal and what are their targets. Physiol. Rev., 87: 905-931, 2007.

Jack C., Knopman D., Jagust W., Shaw L., Aisen P., Weiner M., Petersen R., Tojanowski J. Hypothetical model of dynamic biomarkers of the Alzheimer's pathological cascade. Lancet. Neurol., 9: 119-128, 2010.

Johannessen M., Delghandi M.P., Moens U. What turns CREB on? Cell Signal, 16: 1211-1227, 2004.

Karege F., Lambercy C., Schwald M., Steimer T., Cisse M. Differential changes of cAMP-dependent protein kinase activity and ${ }^{3} \mathrm{H}-\mathrm{c} A M P$ binding sites in rat hippocampus during maturation and aging. Neurosci. Lett., 315: 89-92, 2001.

Kudo K., Wati H., Qiao C., Arita J., Kanba S. Age related disturbance of memory and CREB phosphorylation in CA1 area of hippocampus of rats. Brain Res., 1054: 30-37, 2005.

Kwok R.P., Lundblad J.R., Chrivia J.C., Richards J.P., Bachinger H.P., Brennan R.G. Nuclear protein CBP is a coactivator for the transcription factor CREB. Nature, 370: 223-226, 1994.

Levine R.L. and Stadtman E.R. Oxidative modifications of proteins during aging. Exper. Gerontol., 36: 1495-1502, 2001.

Li Q., Zhao H.F., Zhang Z.F., Liu Z.G., Pei X.R., Wang J.B., Cai M.Y., Li Y. Long-term administration of green tea catechins prevents age-related spatial learning and memory decline in C57BL/6 $\mathrm{J}$ mice by regulating hippocampal cyclic AMPresponse element binding protein signaling cascade. Neuroscience, 159: 1208-1215, 2009a.

Li Q. Zhao H.F., Zhang Z.F., Liu Z.G., Pei X.R., Wang J.B., Li Y. Long-term green tea catechin administration prevents spatial learning and memory impairment in senescence-accelerated mouse prone- 8 mice by decreasing $A \beta$ 1-42 oligomers and upregulating synaptic plasticity-related proteins in the hippocampus. Neuroscience, 163: 741749, $2009 b$.

Liu F.C. and Graybiel A.M. Spatiotemporal dynamics of CREB phosphorylation: transient versus sustained phosphorylation in the developing striatum. Neuron, 17: 1133-1144, 1996.

Lonze B.E. and Ginty D.D. Function and regulation of CREB family transcription factors in the nervous system. Neuron, 35: 605-623, 2002.
Ma Q.L., Harris-White M.E., Ubeda O.J., Simmons M., Beech W., Lim G.P., Teter B., Frautschy S.A., Cole G.M. Evidence of $A \beta$ and transgenedependent defects in ERK-CREB signaling in Alzheimer's models. J. Neurochem., 103: 15941607, 2007.

Matthews R.P., Guthrie C.R., Wailes L.M., Zhao X., Means A.R., McKnight G.S. Calcium/calmodulindependent protein kinase types II and IV differentially regulate CREB-dependent gene expression. Mol. Cell Biol., 14: 6107-6116, 1994.

Mayr B. and Montminy M. Transcriptional regulation by the phosphorylation-dependent factor creb. Nature Rev. Mol. Cell Biol., 2: 599-609, 2001.

McKenna N.J. and O'Malley B.W. Combinatorial control of gene expression by nuclear receptors and coregulators. Cell, 108: 465-474, 2002.

Monti B., Berteotti C., Contestabile A. Dysregulation of memory-related proteins in the hippocampus of aged rats and their relation with cognitive impairment. Hippocampus, 15: 1041-1049, 2005.

Montminy M.R. and Bilezikjian L.M. Binding of a nuclear protein to the cyclic-AMP response element of the somatostatin gene. Nature, 328: 175178, 1987.

Nazarian A., Sun W.L., Zhou L., Kemen L.M., Jenab S., Quinones-Jenab V. Sex differences in basal and cocaine-induced alterations in PKA and CREB proteins in the nucleus accumbens. Psychopharmacology, 203: 641-650, 2009.

Nithianantharajah J. and Hannan A.J. The neurobiology of brain and cognitive reserve: Mental and physical activity as modulators of brain disorders. Progress. Neurobiol., 89: 369-382, 2009.

Paramanik V. and Thakur M.K. Overexpression of mouse estrogen receptor-beta decreases but its transactivation and ligand binding domains increase the growth characteristics of E. coli. Mol. Biotechnol., doi: 10.1007/s12033-010-9308-z, 2010a.

Paramanik, V. and Thakur M.K. Interaction of estrogen receptor associated protein (ERAP) 140 with ER $\beta$ decreases but its expression increases in aging mouse cerebral cortex. Cell Mol. Neurobiol., 30: 961-966, 2010b.

Paramanik V. and Thakur M.K. NMR analysis reveals $17 \beta$-estradiol induced conformational change in ER $\beta$ ligand binding domain expressed in E. coli. Mol. Biol. Rep., doi 10.1007/s11033010-0600-6, 2011a.

Paramanik V. and Thakur M.K. AIB1 shows variation in interaction with ER $\beta T A D$ and expression as 
a function of age in mouse brain. Biogerontology, doi:10.1007/s10522-011-9330-y., 2011b.

Paramanik V. and Thakur M.K. Estrogen receptor $\beta$ and its domains interact with casein kinase 2 , phosphokinase $\mathrm{C}$ and $\mathrm{N}$-myristoylation sites of mitochondrial and nuclear proteins in mouse brain. $J$. Biol. Chem., doi:10.1074/jbc.M112.351262, 2012.

Pekcec A., Baumgärtner W., Bankstahl J.P., Stein V.M., Potschka H. Effect of aging on neurogenesis in the canine brain. Aging Cell, 7: 368-374, 2008.

Porte Y., Buhot M.C., Mons N. Alteration of CREB phosphorylation and spatial memory deficits in aged 129T2/Sv mice. Neurobiol. Aging, 29: 15331546, 2008.

Pugazhenthi S., Wang M., Pham S., Sze C.I., Eckman C.B. Downregulation of CREB expression in Alzheimer's brain and in A $\beta$-treated rat hippocampal neurons. Molec. Neurodegeneration, 6: 60 doi:10.1186/1750-1326-6-60, 2011.

Ramos B.P., Birnbaum S.G., Lindenmayer I., Newton S.S., Duman R.S., Arnsten A.F. Dysregulation of protein kinase a signaling in the aged prefrontal cortex: new strategy for treating age-related cognitive decline. Neuron, 40: 835-845, 2003.

Sandoval S., Pigazzi M., Sakamoto K.M. CREB: A key regulator of normal and neoplastic hematopoiesis. Advan. Hematol., doi:10.1155/2009/634292, 2009.

Satoh J., Tabunoki H., Arima K. Molecular network analysis suggests aberrant CREB-mediated gene regulation in the Alzheimer disease hippocampus. Dis. Markers, 27: 239-252, 2009.

Saura C.A., Choi S.Y., Beglopoulos V., Malkani S., Zhang D., Shankaranarayana Rao B.S., Chattarji S., Kelleher R.J. $3^{\text {rd }}$. Kandel E.R., Duff K., Kirkwood A., Shen J. Loss of presenilin function causes impairments of memory and synaptic plasticity followed by age-dependent neurodegeneration. Neuron, 42: 23-36, 2004.

Saura C.A. and Valero J. The role of CREB signaling in Alzheimer's disease and other cognitive disorders. Rev. Neurosci., 22: 153-169, 2011.

Screaton R.A., Conkright M.D., Katoh Y. The CREB coactivator TORC2 functions as a calcium- and cAMPsensitive coincidence detector. Cell, 119: 61-74, 2004.

Shaywitz A.J. and Greenberg M.E. CREB: a stimulus induced transcription factor activated by a diverse array of extracellular signals. Anal. Rev. Biochem., 68: 821-861.

Sheng M., McFadden G., Greenberg M.E. Membrane depolarization and calcium induce c-fos transcrip- tion via phosphorylation of transcription factor CREB. Neuron, 4: 571-582, 1990.

Silva A.J., Kogan J.H., Frankland P.W., Kida S. CREB and memory. Annu. Rev. Neurosci., 21: 127-148, 1998 .

Silva A.J., Zhou Y., Rogerson T., Shobe J., Balaji J. Molecular and cellular approaches to memory allocation in neural circuits. Science, 326: 391395, 2009.

Snyder E.M., Nong Y., Almeida C.G., Paul S., Moran T., Choi E.Y., Nairn A.C., Salter M.W., Lombroso P.J., Gouras G.K., Greengard P. Regulation of NMDA receptor trafficking by amyloid- $\beta$. Nat. Neurosci., 8: 1051-1058, 2005.

Sun P., Enslen H., Myung P.S., Maurer R.A. Differential activation of CREB by $\mathrm{Ca}^{2+} /$ calmodulin-dependent protein kinases type II and type IV involves phosphorylation of a site that negatively regulates activity. Genes Dev., 8: 2527-2539, 1994.

Thakur M.K. and Paramanik V. Role of steroid hormone coregulators in health and disease. Horm. Res., 71: 194-200, 2009.

Thakur M.K. and Paramanik V. Expression of Trk A and Src and their interaction with ER $\beta$ ligand binding domain show age and sex dependent alteration in mouse brain. Neurochem. Res., doi 10.1007/ s11064-011-0631-y, 2011.

Tully T., Bourtchouladze R., Scott R., Tallman J. Targeting the CREB pathway for memory enhancers. Nat. Rev., 2: 267-277, 2003.

Vitolo O.V., Sant'Angelo A., Costanzo V., Battaglia F., Arancio O., Shelanski M. Amyloid $\beta$-peptide inhibition of the PKA/CREB pathway and longterm potentiation: reversibility by drugs that enhance cAMP signaling. Proc. Natl. Acad. Sci. USA, 99: 13217-13221, 2002.

Wang R., Zhang Y.W., Sun P., Liu R., Zhang X., Xia K., Xia J., Xu H., Zhang Z. Transcriptional regulation of PEN-2, a key component of the $\gamma$-secretase complex, by CREB. Mol. Cell. Biol., 26: 13471354, 2006.

Wang Y., Ghezzi A., Yin J.C., Atkinson N.S. CREB regulation of $\mathrm{BK}$ channel gene expression underlies rapid drug tolerance. Genes Brain Behav., 8: 369-376, 2009.

Williams C.M., El Mohsen M.A., Vauzour D., Rendeiro C., Butler L.T., Ellis J.A., Whiteman M. Spencer J.P. Blueberry-induced changes in spatial working memory correlate with changes in hippocampal CREB phosphorylation and brain derived neurotrophic factor (BDNF) levels. Free Radic. Biol. Med., 45: 295-305, 2008. 
Wu G.Y., Deisseroth K., Tsien R.W. Spaced stimuli stabilize MAPK pathway activation and its effects on dendritic morphology. Nat. Neurosci., 4: 151158, 2001.

Xu J., Rong S., Xie B., Sun Z., Deng Q., Wu H., Bao W., Wang D., Yao P., Huang F., Liu L. Memory impairment in cognitively impaired aged rats associated with decreased hippocampal CREB phosphorylation: reversal by procyanidins extracted from the lotus seedpod. J. Gerontol. A Biol. Sci. Med. Sci., 65: 933-940, 2010.

Yan Z., Feng J., Fienberg A., Greengard P. D(2) dopamine receptors induce mitogen-activated protein kinase and cAMP response element-binding protein phosphorylation in neurons Proc. Natl. Acad. Sci. USA, 96: 11607-11612, 1999.

Zhang Y., Kornhauser J.M., Zee P.C., Mayo K.E., Takahashi J.S., Turek F.W. Effects of aging on light-induced phase-shifting of circadian behavioral rhythms. FOS expression and CREB phosphorylation in the hamster suprachiasmatic nucleus. Neuroscience, 70: 951-961, 1996.

Zhao H., Li Q., Pei X., Zhang Z., Yang R., Wang J., $\mathrm{Li} \mathrm{Y}$. Long-term ginsenoside administration prevents memory impairment in aged C57BL/6J mice by up-regulating the synaptic plasticity-related proteins in hippocampus. Behav. Brain Res., 201: 311-317, 2009. 